\title{
A Curricular Innovation to Promote Interprofessional Collaboration
}

\author{
Beth W. Liston ${ }^{1, *}$, Janet Wagner ${ }^{2} \&$ Jackie Miller $^{2}$ \\ ${ }^{1}$ College of Medicine, The Ohio State University, Columbus, OH 43210, USA \\ ${ }^{2}$ Columbus State Community College, Columbus, OH 43215, USA \\ *Corresponding author: The Ohio State University, A150B Starling-Loving Hall 320 W. $10^{\text {th }}$ Avenue, Columbus, \\ OH 43210, USA Tel: 1-614-293-7499 E-mail: Beth.Liston@osumc.edu
}

Received: December 11, 2012 Accepted: January 15, $2013 \quad$ Online Published: January 28, 2013

doi:10.5430/jct.v2n1p68 URL: http://dx.doi.org/10.5430/jct.v2n1p68

\begin{abstract}
Background: Interprofessional teamwork is a crucial competency in health professions education which improves patient care. However, interprofessional education is not a widespread practice in medical schools. To address this need, we developed an educational pilot utilizing a standardized patient simulation to teach interprofessional communication and teamwork to medical and nursing students. Methods: Ten teams of students consisting of a fourth year medical student, a senior nursing student and a patient family member (portrayed by a standardized actress) participated in a simulated scenario involving end-of-life decision making for a critically ill patient. Interprofessional teamwork and communication were essential to successfully determine next steps when a 'code blue' was called. Results: This exercise was well received and medical students felt more prepared to work on an interprofessional team after completion. Conclusions: Simulation is an effective method for teaching interprofessional teamwork and communication to medical students and nursing students.
\end{abstract}

Keywords: interprofessional education; interdisciplinary; medical student; nursing student; education; simulation; standardized patient

\section{Introduction}

Health care is rapidly changing and the need for interprofessional collaboration and teamwork is growing. Technological advances, health care legislation, the explosion of knowledge in the health sciences and the perceived fragmentation of care have created an urgent need for the development of enhanced competencies and roles for health care practitioners. Calls for reform have been issued by political entities and health professionals (Cooke, Irby, \& O'Brien, 2010). Lack of effective communication is a key predictor of safety issues particularly between members of different health care professionals (Alvarez \& Coiera, 2006). All individuals in the health care setting need to be able to work effectively as part of a functioning team. Understanding and valuing the nuances relating to both the traditional and evolving roles of all members of the health care team other than self promotes team building as well as decreases redundancy thus promoting the provision of high quality health care. Medical educators must be cognizant of these new needs and incorporate innovative teaching strategies to help students be prepared for these new realities. Interprofessional education (IPE) is one such strategy. This article will describe the design and pilot implementation of an IPE simulation involving medical and nursing students in an end -of life scenario. Lessons from this pilot will help medical education address needed reforms.

As the health care system changes and evolves, quality and safety issues continue to emerge. The Joint Commission on Accreditation of Healthcare sentinel event reporting has indicated that $70 \%$ of preventable medical errors are due to communication issues. Several reports by the Institute of Medicine have suggested that quality of care and patient safety is being compromised in the current fragmented health care delivery system (Greiner \& Knebel, 2003)(Kohn, Corrigan, \& Donaldson, 2000). They recommend that all health care practitioners be grounded in five core competencies one of which relates to the ability to work effectively in teams. Obviously these new skills need to be part of the educational experience of health students. Unfortunately most health education is delivered in silos allowing the student to understand only one reality or world view. However in most professions, health care educators are looking at these recommendations and beginning to respond through curriculum revision. Medicine is 
no exception and multiple international organizations are working to develop programs (Barnsteiner, Disch, Hall, Mayer, \& Moore, 2007). Spurred to some degree by the Carnegie Report for Medical Education, curriculum innovation is being explored. One such innovation that holds promise for possibly changing the dynamics within the health care system is the infusion of learning experiences that promote the development of interprofessional education.

The health care professionals that have historically had the most difficulty working in collaboration are physicians and nurses. While these groups have a common goal in terms of patient outcome at times their responsibilities overlap and each group uses both similar and dissimilar types of knowledge to justify their clinical work (Stein-Parbury \& Liaschenko, 2007). Because of this they have a tumultuous history dating back many years to an era when males dominated medicine and only woman were nurses. Societal gender roles were rigidly prescribed and therefore each played a "game". There was a tacit understanding between groups that allowed the nurses to covertly participate in clinical decision making without ever appearing to do so. This "game" involved the use of a coded language in which the nurse covertly offered respectful "suggestions" about patient needs that were then acted on by the physician (Stein, 1967) This "game" worked well but in recent years there have been substantive changes in the interactional style between these two groups (Sirota, 2008). Roles have changed without clear rules emerging and at times conflict occurs. While generally not totally overt this conflict if not recognized, negotiated and resolved can threaten care. Both medicine and nursing education programs spend valuable time in isolation trying to help their students understand the rules of the game. Medical students/ residents try to determine how to get the nursing staff to follow their orders and nursing students/novice nurses try to figure out how to get the doctors to order what their patient's need. Studies on teamwork demonstrate that physicians and nurses view collaboration differently (Makary et al., 2006). To resolve these discrepancies, both must learn negotiation and conflict-resolution skills (Wagner, Liston, \& Miller, 2011). Clearly the pairing of these two groups within their formative educational training is important.

Interprofessional education as defined by Hammick et al as those occasions when members (including students)of two or more professions learn with, from and about one another to improve collaboration and the quality of care (Hammick, Freeth, Koppel, Reeves, \& Barr, 2007). The idea of collaboration and team has been in the literature for a number of years. Data is accumulating regarding the practice based changes that have proved promising in improving health care and patient outcomes (Zwarenstein, Goldman, \& Reeves, 2009). In practice settings there have been some studies that indicate interprofessional collaboration is effective and can improve health care processes and outcomes (Zwarenstein et al., 2009). Within internal medicine there is also a growing body of research showing measurable effects on care. Decreased functional decline and decreased in-hospital mortality have been linked to the presence of structured care teams and in ICU's there are improved there are improved patient outcomes (Baggs et al., 1999; Der, 2009; Kim, Barnato, Angus, Fleisher, \& Kahn, 2010; Mudge, Laracy, Richter, \& Denaro, 2006). There seems to be a consensus in the published literature on the need for an interprofessional component in health professionals' education to enable medical students to be prepared to deliver this high quality care. While there is no clear consensus on the ideal timing of an IPE intervention many have suggested that this team training be imbedded throughout health professions education (Zwarenstein, Reeves, \& Perrier, 2005)(Hall \& Weaver, 2001). In medicine it is reasonable that this content be given during the clinical portion of the student's education (Liston, Fischer, Way, Torre, \& Papp, 2011). Research done related to successful student outcomes for IPE projects indicate that students respond better if the processes are customized and reflect the reality of either current or future practice for participants. Sustained effects on attitudes towards interprofessional competence are seen when didactic and clinical experiences are combined (Morison \& Jenkins, 2007). Successful strategies for IPE include challenging students with increasingly complex, reality-based tasks as part of the learning process (D'Eon, 2005). In addition, authentic experiences using simulation produce more positive results (Hammick et al., 2007). To address the changing health care environment, the need for medical education reform and the data suggesting interprofessional collaboration leads to improved quality of care, we developed an educational pilot utilizing a standardized patient simulation to teach interprofessional communication and teamwork between medical students and nursing students.

\section{Methods}

A patient scenario was created collaboratively by medical school and nursing education faculty and staff from the Ohio State University Clinical Skills Laboratory to stimulate discussion and teamwork (Wagner et al., 2011). Volunteers were solicited from fourth-year medical students at the Ohio State University (OSU) and senior nursing students at Columbus State Community College. They were randomly assigned to create ten inter-professional teams 
participating in the scenario. Standardized actresses were trained by the medical school faculty member at the Clinical Skills Center regarding their role as a family member as well as the details of the setup.

\subsection{Overview}

The scenario presented a critically ill patient in whom end - of- life decisions were necessary and students were required to work together to effectively make these decisions. The patient was an elderly woman presenting from an extended care facility to an emergency room (ER) because of worsening distress and hypoxia. Each student received information about the patient reflective of the real-life hand-off practices at OSU. The medical students received a brief summary of the chief complaint, ER findings and course. They were informed that the patient had become confused, was rapidly worsening, and they had just been paged by nursing to speak with the patient's daughter who had just arrived with many questions. The nursing students received an initial nursing assessment with the added information that the patient had metastatic cancer. They were also informed that they had spoken with the patient while the patient was alert and oriented. The patient had told the nursing student that she knew she had metastatic cancer, had refused chemotherapy and that she did not want any life support. Her written advanced directives were at her long term care facility where she resided. The standardized actress was to portray the daughter of the patient. She was instructed to ask questions and insist that the medical team must 'save' her mother. The patient's daughter, as portrayed by the standardized actress, was unaware of her mother's advanced directives although she did know about her decision to refuse chemotherapy and consider hospice. The standardized actress knew that interprofessional teamwork was the goal of the scenario and was instructed to allow the team to lead her to a conclusion (either intubation or comfort care) as long as they had effectively communicated with her and each other, acting as a team.

\subsection{Mechanics}

The scenario was conducted in the OSU Clinical Skills laboratory which contains rooms equipped with two-way mirrors and video/audio recording equipment. Nursing students were given their information with three minutes to review, they then entered the room. The standardized actress immediately entered the back of the room asking for information and voicing her desire 'for everything to be done'. Nursing students then had five minutes to comfort and communicate with the standardized actress, during which time the medical student was reading their hand-off information. The medical students then entered the room to communicate with the nursing student and the family member with the instructions to exit after a plan of care was developed. Five minutes into the session, an announcement was made, "Attention medical team, your patient's oxygen saturation is now $85 \%$ on $100 \%$ oxygen". After 10 minutes, a code blue was called and both students were instructed to leave and consider their next steps. Medical students were given 5 minutes to document their assessment and plan. Nursing students were then given 5 minutes to review and respond to the medical student's note.

\subsection{Discussion}

All students and the standardized actress participated in a de-briefing session immediately following the scenario. Videos were shown of several of the team interactions to review and assess communication and teamwork as a group. Students were asked to describe the ethical framework used in their thought process. Both nursing students and medical students were asked to self-evaluate and provide feedback to each other on the team interaction and decision making. The standardized actress provided information on the patient's perspective of the medical student and nursing student performance. The video/audio recordings of this simulation were saved and are used to stimulate discussion on communication and teamwork in other places within medical school and nursing school curricula.

\section{Results}

All teams developed an assessment and plan for their critically ill patient that was accepted by the standardized patient. Medical students responded positively to items on a formal evaluation tool using a 5-point Likert Scale (Table 1). Students felt the patient scenario and feedback sessions were valuable learning exercises. They felt better prepared to work on a multidisciplinary team as a result of this session and would recommend the course to other students. Medical student comments indicate that the exercise taught them the value of nurse/physician communication and the importance of discussing patient details with nurses (Table 2). 
Table 1: Medical Student Responses

\begin{tabular}{llc}
\hline Questions & $\begin{array}{l}\text { Average } \\
\text { Response } \\
(\mathrm{n}=10)\end{array}$ & $\begin{array}{c}\text { Standard } \\
\text { deviation }\end{array}$ \\
\hline 1. The standardized patient scenario was a valuable learning exercise & 4.3 & 0.46 \\
2. The feedback session was a valuable learning exercise & 4.5 & 0.50 \\
3. I will be better prepared to discuss advanced directives as a result of this session & 4.1 & 0.70 \\
4. I will be better able to work on a multidisciplinary team as a result of this session & 4.3 & 0.64 \\
5. I would recommend this to other students & 4.3 & 0.67 \\
\hline
\end{tabular}

Table 2: Medical Student Comments

1. The take home for me is that "you should assume that you don't know all the details." I think this was extremely valuable in bridging the communication gap between physicians and nurses.

2. I feel this mirrored real-life situation quite well. I think it benefited most parties involved and if anything it was a good exposure to this type of circumstance/communication debacle.

3. I felt that I had very little info walking into the room- was not at all sure what I was supposed to do which contributed to not asking enough questions of the nurse and not getting details on the advance directive soon enough.

4. Helps you learn some basics about working with limited info- when it comes to advanced directives.

5. It is interesting. I think that both advanced directives and a multidisciplinary team is necessary for medical students but it is not discussed with medical students.

5. This was great to help me see ways that I can better communicate with others in health care positions. I will definitely take more time to further elicit information from nurses/others.

6. Great experience to work with nursing students and get immediate feedback from standardized patients. Valuable to include in medical school to emphasize multidisciplinary teamwork.

7. It was helpful to interact with the patient and nurse because it will happen in the real world this way and even though we have some training with the SP's, we don't get the interaction with nurses. It would probably be good training for the nursing students to work with SP's.

8. This is a good idea for a practice exercise. I do feel that the actual learning experience was too little, too rushed and too awkward. Having said that, I do believe this was a valuable experience because of what it will be in the future when the idea is streamlined and built upon. I have to tell you I really enjoyed the interaction with nursing students; this is the first such interaction I have had in medical school.

\section{Conclusions}

Interprofessional communication can be effectively fostered in medical education. Medical students indicated receiving real benefit from this type of experience that would help guide their future practice, although rigorous study would be needed to address the longevity of this benefit. Previous data have demonstrated the effects of pre-licensure interprofessional education interventions to be equivocal (Zwarenstein et al., 2005). However, interventions most likely to be effective involve authentic, complex, challenging, reality-based situations (D'Eon, 2005; Hammick et al., 2007) such as the one created in this experience. The simulation highlighted the need for teamwork and discussion in patient care, particularly in critical conversations. Few students had had exposure to this type of experience in the past and medical student/nursing student interactions were not previously part of the curriculum, reflecting the national practice in interprofessional education (Liston et al., 2011). Recently, core competencies for interprofessional collaborative practice were identified as values/ethics for interprofessional practice, roles/responsibilities, interprofessional communication and teams and teamwork (Core competencies for interprofessional collaborative practice: Report of an expert panel.2011). This intervention addresses all four. In our scenario, students of two different professions were required to work in teams and communicate with one another. During the feedback session students were able to discuss their respective roles within the scenario as well as the 
values that contributed to their decision making processes.

This project identified some barriers to interprofessional education. Professional attitudes and preconceptions lead to discomfort that was alleviated by this exercise. Medical students naturally felt the need to lead the team, even in this setting in which they had limited information. In contrast, some of the nursing students felt uncomfortable participating in the medical decision making. During the feedback session, one medical student indicated afterward that he was surprised by how much the nursing student knew about the patient and that he would never again assume he had all of the necessary information. Additional barriers encountered were consistent with those identified in the literature - including scheduling alignment, time in the existing curriculum and resources including money (Liston et al., 2011). For this simulation volunteers were used from senior medical student and nursing courses, and the standardized patient and simulation center was supported by the medical school. This worked well with our small group setting but would be more difficult and costly to scale for the entire student body.

Nonetheless, this simulation provided valuable re-usable educational materials. Recordings of these scenarios allow for additional courses to review these and assess the interprofessional teamwork and interactions. Medical students and nursing students watch these tapes asynchronously and are brought together virtually, on conference calls or in person to stimulate discussion on this crucial competency. This readily available technology assists in overcoming identified barriers such as scheduling, time and money for future students.

In summary, this pilot was an effective and well-received educational intervention for medical students that created valuable educational materials. This is a beginning step in a culture that fosters interprofessional teamwork in health care. Additional curriculum development is needed to foster interprofessional collaboration to assure high quality patient care.

\section{Competing interests/conflict of interests}

The authors declare that they have no competing interests.

\section{References}

Alvarez, G., \& Coiera, E. (2006). Interdisciplinary communication: An uncharted source of medical error?. Journal of Critical Care, 21(3), 236-242. http://dx.doi.org/10.1016/j.jcrc.2006.02.004

Baggs, J. G., Schmitt, M. H., Mushlin, A. I., Mitchell, P. H., Eldredge, D. H., Oakes, D., \& Hutson, A. D. (1999). Association between nurse-physician collaboration and patient outcomes in three intensive care units. Critical Care Medicine, 27(9), 1991-1998. http://journals.lww.com/ccmjournal/pages/default.aspx

Barnsteiner, J., Disch, J., Hall, L., Mayer, D., \& Moore, S. (2007). Promoting interprofessional education. Nursing Outlook, 55(3), 144-150. http://dx.doi.org/10.1016/j.outlook.2007.03.003

Cooke, M., Irby, D. M., \& O'Brien, B. C. (2010). Education physicians: A call for reform of medical school and residency. San Francisco, CA: Jossey-Bass.

Core competencies for interprofessional collaborative practice: Report of an expert panel. (2011). Washington, D.C.: $\begin{array}{llll}\text { Interprofessional } & \text { Education } & \text { Collaborative. } & \text { Retrieved }\end{array}$ http://www.aacn.nche.edu/education-resources/ipecreport.pdf

D'Eon, M. (2005). A blueprint for interprofessional learning. Journal of Interprofessional Care, 19 Suppl 1, 49-59. http://dx.doi.org/10.1080/01421590400004924

Der, Y. (2009). Multidisciplinary rounds in our ICU: Improved collaboration and patient outcomes. Critical Care Nurse, 29(4), 84. http://dx.doi.org/10.4037/ccn2009792

Greiner, A. C., \& Knebel, E. (Eds.). (2003). Health professions education: A bridge to quality. Washington, D.C.: The National Academies Press.

Hall, P., \& Weaver, L. (2001). Interdisciplinary education and teamwork: A long and winding road. Medical Education, 35(9), 867-875. http://onlinelibrary.wiley.com/journal/10.1111/(ISSN)1365-2923

Hammick, M., Freeth, D., Koppel, I., Reeves, S., \& Barr, H. (2007). A best evidence systematic review of interprofessional education: BEME guide no. 9. Medical Teacher, 29(8), 735-751. http://dx.doi.org/10.1080/01421590701682576

Kim, M., Barnato, A., Angus, D., Fleisher, L., \& Kahn, J. (2010). The effect of multidisciplinary care teams on 
intensive care unit mortality. Archives of Internal Medicine, 170(4), 369-376. http://dx.doi.org/10.1001/archinternmed.2009.521

Kohn, L., Corrigan, J., \& Donaldson, M. S. (2000). To err is human: Building a safer health care system. Washington, DC: National Academy Press.

Liston, B., Fischer, M., Way, D., Torre, D., \& Papp, K. (2011). Interprofessional education in the internal medicine clerkship: Results from a national survey. Academic Medicine, 86(7), 872-876. http://dx.doi.org/10.1097/ACM.0b013e31821d699b

Makary, M., Sexton, J., Freischlag, J., Holzmueller, C., Millman, E., Rowen, L., \& Pronovost, P. (2006). Operating room teamwork among physicians and nurses: Teamwork in the eye of the beholder. Journal of the American College of Surgeons, 202(5), 746-752. http://dx.doi.org/10.1016/j.jamcollsurg.2006.01.017

Morison, S., \& Jenkins, J. (2007). Sustained effects of interprofessional shared learning on student attitudes to communication and team working depend on shared learning opportunities on clinical placement as well as in the classroom. Medical Teacher, 29(5), 464-470. http://dx.doi.org/10.1080/01421590701477381

Mudge, A., Laracy, S., Richter, K., \& Denaro, C. (2006). Controlled trial of multidisciplinary care teams for acutely ill medical inpatients: Enhanced multidisciplinary care. Internal Medicine Journal, 36(9), 558-563. http://dx.doi.org/10.1111/j.1445-5994.2006.01135.x

Sirota, T. (2008). Nursing2008 nurse/physician relationships survey report. Nursing, 38(7), 28-31. http://dx.doi.org/10.1097/01.NURSE.0000325339.15071.08

Stein, L. I. (1967). The doctor-nurse game. Archives of General Psychiatry, 16(6), 699-703. http://archpsyc.jamanetwork.com/journal.aspx

Stein-Parbury, J., \& Liaschenko, J. (2007). Understanding collaboration between nurses and physicians as knowledge at work. American Journal of Critical Care, 16(5), 470-477. http://ajcc.aacnjournals.org/

Wagner, J., Liston, B., \& Miller, J. (2011). Developing interprofessional communication skills. Teaching and Learning in Nursing, 6, 97-101. http://dx.doi.org/10.1016/j.teln.2010.12.003

Zwarenstein, M., Goldman, J., \& Reeves, S. (2009). Interprofessional collaboration: Effects of practice-based interventions on professional practice and healthcare outcomes. Cochrane Database Syst Rev, 4(3), CD000072. http://dx.doi.org/10.1002/14651858.CD000072.pub2

Zwarenstein, M., Reeves, S., \& Perrier, L. (2005). Effectiveness of pre-licensure interprofessional education and post-licensure collaborative interventions. Journal of Interprofessional Care, 19 Suppl 1, 148-165. http://dx.doi.org/10.1080/13561820500082800 